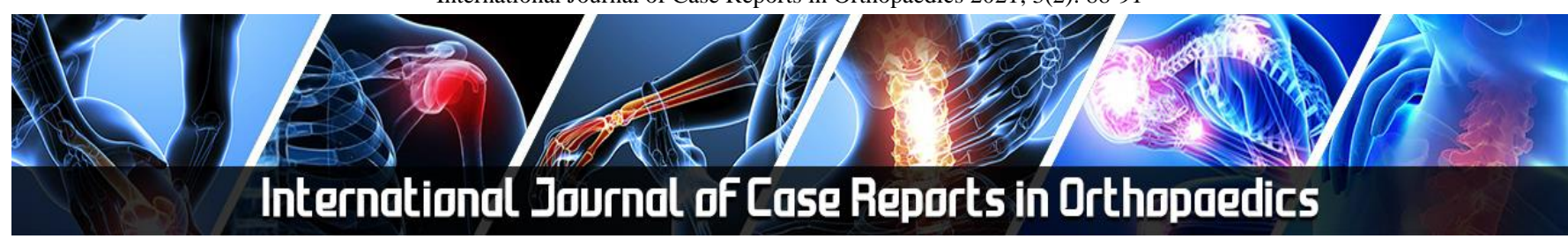

E-ISSN: 2707-8353

P-ISSN: 2707-8345

IJCRO 2021; 3(2): 88-91

Received: 13-06-2021

Accepted: 15-07-2021

Andrew Isaac Christudoss

Department of Trauma and Orthopaedic Surgery, Padhar

Hospital, Betul, Madhya

Pradesh, India
Corresponding Author: Andrew Isaac Christudoss Department of Trauma and Orthopaedic Surgery, Padhar Hospital, Betul, Madhya Pradesh, India

\section{A simple technique of removal of a stripped and incarcerated cannulated screw adjacent to the calcar in the femoral neck in a resource-limited setting: A case report}

\author{
Andrew Isaac Christudoss
}

DOI: $\underline{\text { https://doi.org/10.22271/27078345.2021.v3.i2b.72 }}$

\begin{abstract}
Osteosynthesis of fracture neck of the femur with multiple cannulated screws is one of the standard techniques used, especially in non-elderly patients. Implant exit from the femoral neck is done in cases with hardware failure, infection, prominence, non-union, and pain among others. The femoral neck is unique due to its precarious blood supply, distribution of forces, and formation of dense trabeculae.

The cannulated screw placed adjacent to the calcar region is known to get incarcerated due to increased osseointegration, bony ingrowth, and bending. These screws can present in various modes of fatigue for which different extraction techniques and sophisticated instruments have been employed, most of which are not readily available at every center. We present a case where a stripped and incarcerated screw was removed using a technique with simple instruments in a resource-limited setting which can be reproduced for any cannulated screw and in any center.
\end{abstract}

Keywords: implant exit, femoral neck screw, stripped, cold-welded, incarcerated, resource-limited setting

\section{Introduction}

Partially threaded cannulated cancellous screws are commonly used for osteosynthesis in femoral neck fractures ${ }^{[1]}$, slipped capital femoral epiphysis, and juxta-articular/ intraarticular fractures ${ }^{[2]}$. These screws can be damaged during the process of initial internal fixation, during fracture healing, or at the time of implant exit ${ }^{[2]}$. Cannulated screws usually present with difficulty during extraction because of excessive bony in-growth and increased osseointegration with a solid hold in the dense cancellous bone, which requires extreme torque during removal ${ }^{[3]}$. Apart from this, they can also be bent, broken, buried, and/or can migrate.

Implant removal is warranted when there is persistent pain, prominence of implant, bursitis, infection, hardware fatigue, migration, patient preference, loosening, and before secondary surgery for non-union, malunion, or joint replacement ${ }^{[4,5]}$. Quite often implant removal surgery is more time-consuming than the initial fixation ${ }^{[6]}$ and is associated with complications such as damage or loss of surrounding bone, fracture, deposition of metal debris, infection, and generation of heat ${ }^{[7]}$.

There is no standard technique described to remove stripped and incarcerated cannulated screws. Specialized screw removal sets are employed in most urban facilities but are expensive and not readily available in a rural setup. Some of the techniques using these instruments can be associated with the complications mentioned above ${ }^{[7]}$. Surgeons in these settings have to develop tricks and find simple cost effective solutions to tackle these difficult scenarios.

Here we describe a simple technique to remove a symptomatic stripped and incarcerated screw adjacent to the calcar in a middle-aged man in the setting of a malunited fracture neck of the femur with post-traumatic secondary arthritis of the hip. This technique utilizes instruments such as Harrington rod cutter, AO drill chuck, T-handle which are cost effective and was completed in a short duration without any complications.

Case Report

A 43-year-old daily wage worker presented to our out-patient clinic in a mission hospital 
located in rural central India with complaints of restriction in movements of his right hip for 18 months, pain in the hip, and prominence of the implant for 30 months. He had a history of fall 3 years ago following which he sustained a closed isolated trauma to his right hip joint. He was diagnosed to have a fracture in the hip and underwent open reduction and internal fixation at a private centre. He had an uneventful postoperative course. Four months following the surgery he started weight bearing which is when he noticed the pain and limp. At present he is unable to sit crosslegged, squat, sleep in the right lateral position, and has not been able to go to work since the injury. He ambulates using a stick as an aid. Examination of his right lower limb revealed a scar $11 \mathrm{~cm}$ in length along the proximal lateral aspect of his thigh and significant wasting of the right lower limb. There was tenderness and prominence of the screw heads in the greater trochanteric region. Global restriction of movements associated with pain, spasm, and crepitus was noted. He had $2 \mathrm{~cm}$ true shortening of his right lower limb. There was no neurovascular deficits.

Plain radiographs (Fig 1) showed a mal-united sub-capital neck of femur fracture with the femoral neck in varus, with evidence of advanced arthritis in the femoral head and acetabulum. Three screws were in-situ in an inverted triangle configuration. There were no signs of loosening. His blood investigations were normal.

He was advised for an implant exit and un-cemented total hip replacement. However, the patient chose to have a staged procedure due to financial constraints.
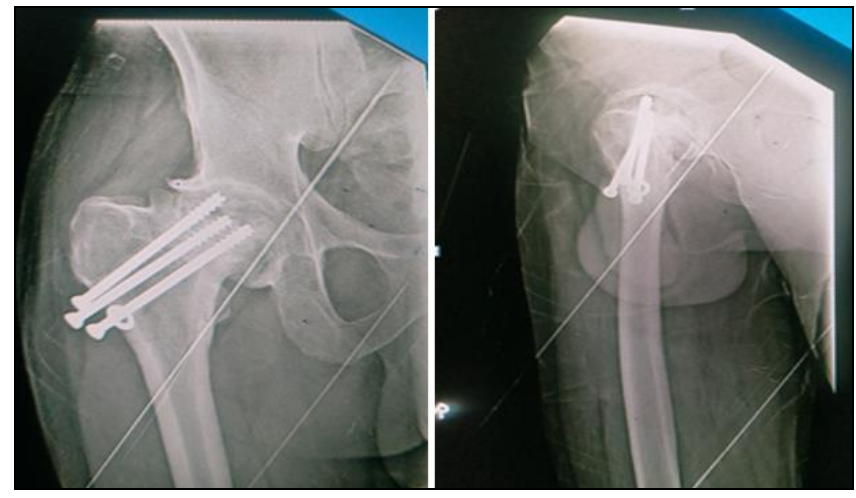

Fig 1: Preoperative plain radiograph of the right hip.

\section{Procedure}

The patient was positioned supine on a radiolucent table and the surgery was performed under spinal anaesthesia. Stab incisions were made directly above the screw heads and they were exposed completely. The 2 superior screws had a solid hold in the bone but were removed intact using a $3.5 \mathrm{~mm}$ solid hexagonal screwdriver. The inferior screw head was stripped and could not be removed. Attempts were made to extract the screw using the interference/filler technique ${ }^{[8,9]}$, Steinmann pins ${ }^{[2]}$ and using various bone pliers, clamps but repeated attempts caused deposition of metallic debris in the soft tissue and failed to move the screw in any direction.

\section{Technical tip}

The incision was extended and $0.5 \mathrm{~cm}$ of the shaft of the screw was exposed. Neither the AO drill chuck nor the T handle fit over the screw head, hence it was cut using a jumbo rod/wire cutter (Figure 2, 3). We preferred the AO drill chuck over the T handle as it had a much better hold on the screw. It was noted that both the T handle and AO drill chuck required $0.4-0.5 \mathrm{~cm}$ of shaft of the screw exposed outside bone for it to be adequately held and tightened (Figure 4 ). The rest of the drill system was attached to the chuck and the screw was removed in reverse mode. The stainless steel screw $(75 \mathrm{~mm}, 6.5 \mathrm{~mm})$ was removed without any damage to the surrounding bone (Figure 5). This simple hack avoided more destructive procedures such as core reaming, multiple drill holes, and dislocation of the femoral head which could beset more complications. The patient had an uneventful postoperative period. He was discharged nonweight bearing with crutches to follow up for a total hip replacement.

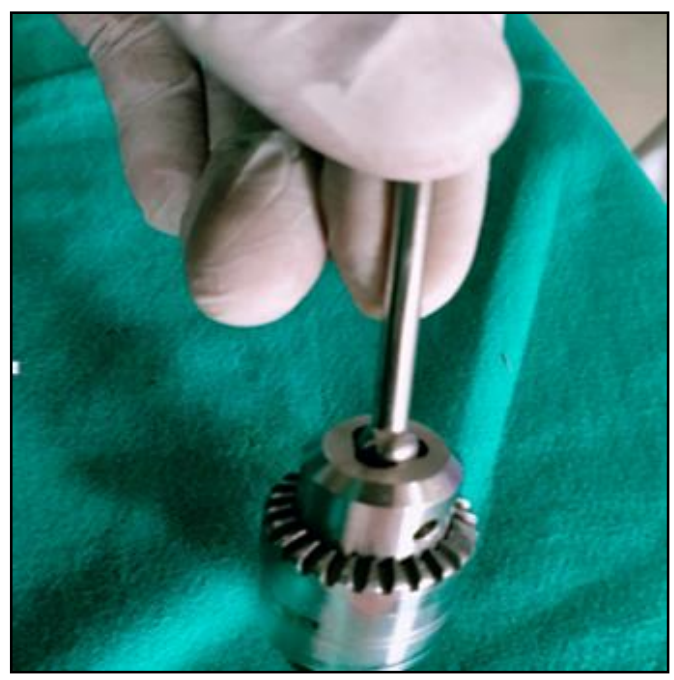

Fig 2: The head of the $6.5 \mathrm{~mm}$ screw could not be held with the drill chuck or T handle;

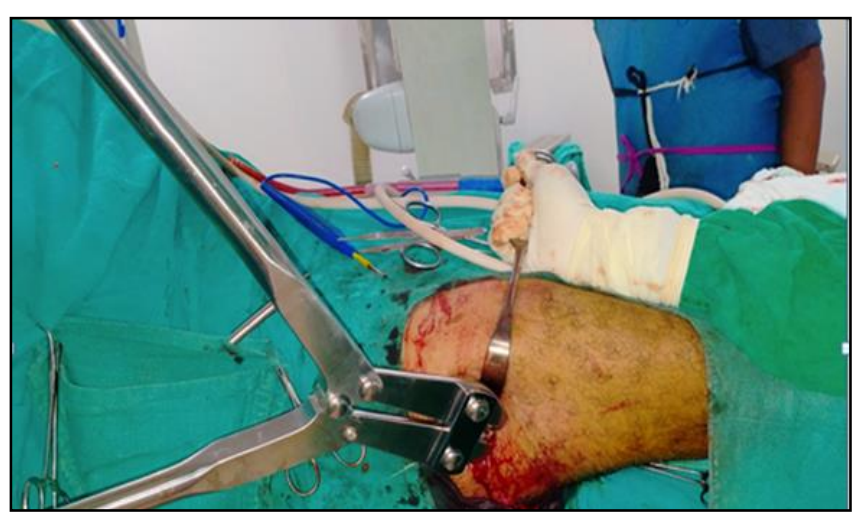

Fig 3: Intraoperative photo showing the head being cut.

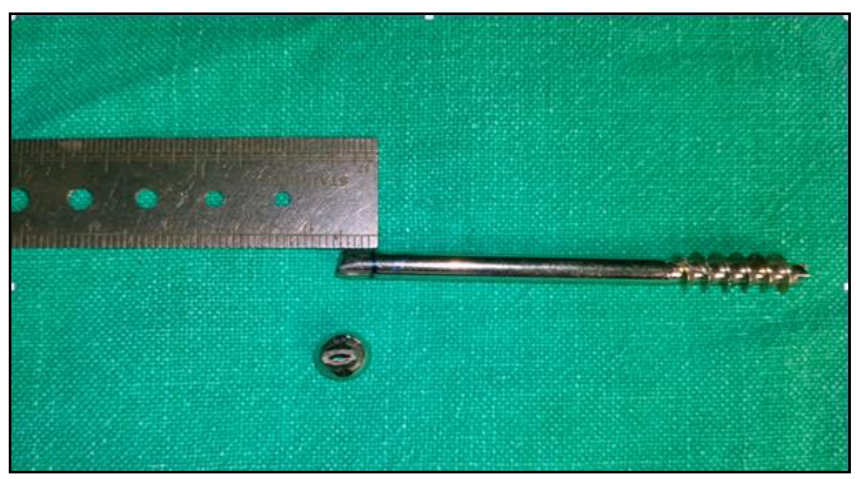

Fig 4: A length of $0.4-0.5 \mathrm{~cm}$ outside the bone is required to achieve hold with the drill. 


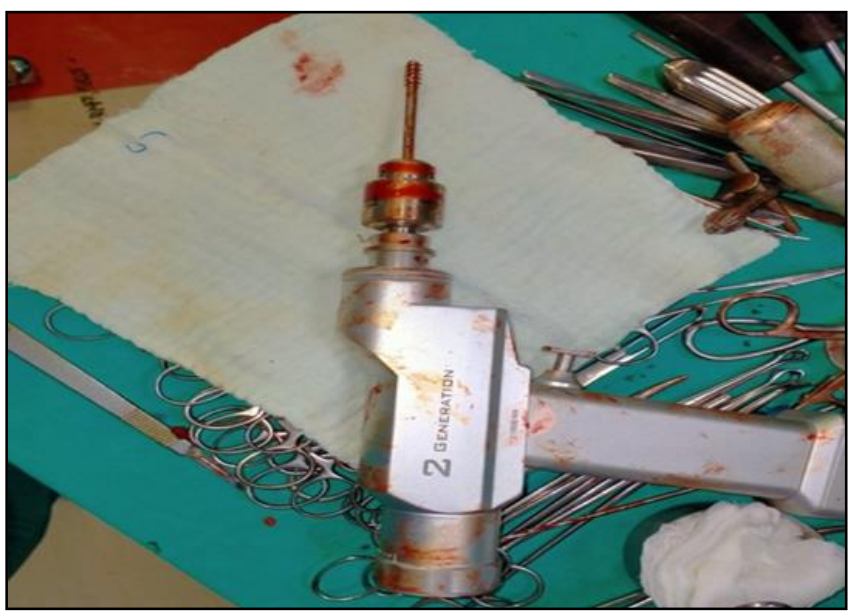

Fig 5: Intraoperative images of screw removed with the drill.

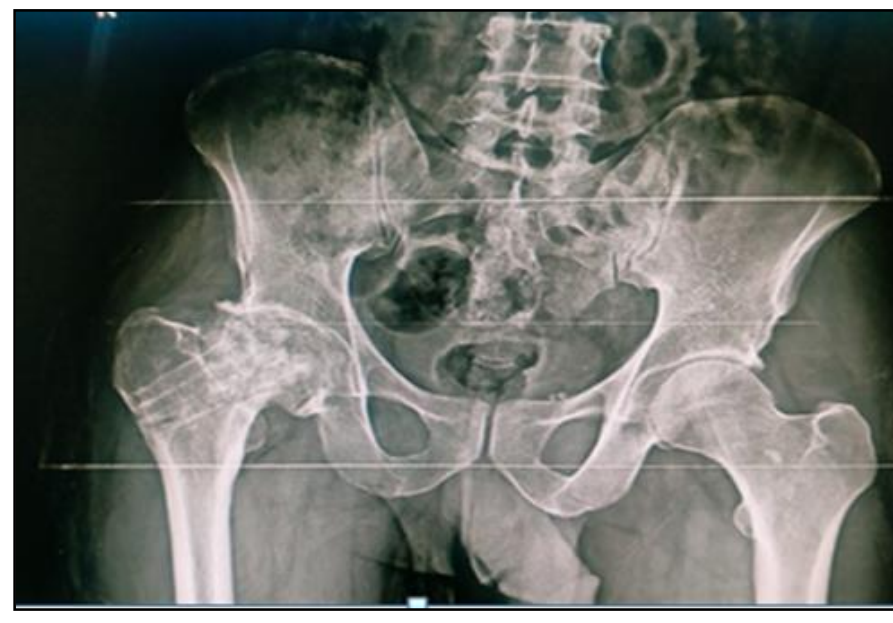

Fig 6: Postoperative radiograph

\section{Discussion}

Cannulated screws are used for osteosynthesis of intraarticular and juxta-articular fractures frequently in recent times with fractured neck of femur being a common indication ${ }^{[1,2]}$. Complications associated with implant removal are screw breakage, infection, retention, scars revision, bone loss, iatrogenic fractures, and prolonged surgery time ${ }^{[2,6,10,11]}$. One such study by Juan et al reported a removal failure rate of $15.7 \%$ for cannulated screws among paediatric patients treated for slipped capital femoral epiphysis.

Incarceration especially adjacent to the calcar, occurs due to the shear forces acting across the femoral neck which remodel the bony trabeculae pattern leading to a solid hold of the screw in the dense cancellous bone ${ }^{[12]}$. Bony ingrowth and abnormal bending are other causes. Stripping of the screw head can occur during removal due to the increased torque required to remove these incarcerated screws and more commonly seen in titanium screws ${ }^{[2]}$.

Various techniques have been described for the removal of the cannulated screws. Many of these techniques are simple, use basic instruments, and are unique to the situation encountered by the operating surgeon. Summarised below in (table 1) is a list of techniques described to remove cannulated screws.

Table 1: Showing is a list of techniques described to remove cannulated screws.

\begin{tabular}{|c|c|c|}
\hline Study & Technique & Comments/Indication \\
\hline $\begin{array}{l}\text { Yongshengchen et } \\
\text { al. }{ }^{[13]}\end{array}$ & A guidewire and countersink technique. & $\begin{array}{l}\text { Deeply buried cannulated screws in } \\
\text { osteoporotic bone or with bone/soft tissue } \\
\text { overgrowth. }\end{array}$ \\
\hline $\begin{array}{c}\text { Pattison et al. }{ }^{[9]} \\
\text { Bhutta } \text { et al. }{ }^{[8]} \\
\end{array}$ & Interference Technique/Filler Technique & Stripped screw head \\
\hline Tomar et al. ${ }^{[12]}$ & Dislocation of the hip joint and removal from the head /neck end. & $\begin{array}{l}\text { Useful when Total Hip arthroplasty is planned } \\
\text { at the same sitting. }\end{array}$ \\
\hline Stafford et al. ${ }^{[3]}$ & Solid Hexagonal/Stardrive screwdrivers as opposed to cannulated ones & $\begin{array}{c}\text { Have higher fatigue strength compared to the } \\
\text { cannulated drivers. }\end{array}$ \\
\hline Stafford et al. ${ }^{[3]}$ & Vice Grip+Conical reverse cutting male threaded tap ( Synthes set) & Stripped head \\
\hline Stafford et al. ${ }^{[3]}$ & Trephine reamer+ Reverse cutting female threaded tap(Synthes set) & Broken and buried screws \\
\hline Zhao et al. ${ }^{[14]}$ & Bent steel sternal wire+ cannulated driver & Deeply positioned screw in the pelvis \\
\hline SS Kaleel et al. ${ }^{[11]}$ & $\begin{array}{l}\text { Set of Steinman pin and bone cement } \\
\text { Set of Allen keys }\end{array}$ & Stripped screw head or incarcerated screw \\
\hline Gruber et al. ${ }^{[15]}$ & Cannulated reamer + Cannulated T- handle Trephine & Buried but intact head \\
\hline Moehring et al. ${ }^{[2]}$ & Steinman pin and T handle /drill & Stripped and incarcerated screw \\
\hline
\end{tabular}

Removal of cannulated screws can be challenging. The inferior calcar screw is known to cause difficulties during extraction ${ }^{[12]}$ and in some cases, it has been cut at the level of the bone and retained in the neck ${ }^{[6]}$. Most often stripping of the head occurs during removal which results in the screw being partially exposed. Osteotomes, drills, burrs, or other procedures using excessive force should be avoided if possible. In most resource-limited setting special screw removal sets are not available and hence one has to rely on conventional methods or innovate simple techniques using available resources. The aim was to remove the screw safely; quickly, avoid bone loss and further weakening at 
the femoral neck region. Instruments used here such as a jumbo cutter, T handle, and drill are available at all centres. This technical tip can be used for the extraction of screws in a similar unique situation in any other location. However, it does have limitations such as ${ }^{[1]}$ The screw has to be prominent or will have to be brought out by at least $0.4 \mathrm{~cm}$ $0.5 \mathrm{~cm}$ before applying the drill chuck ${ }^{[2]}$ The incision will have to be large enough to accommodate the drill chuck.

\section{Conclusion}

Removal of a cancellous screw from the inferior femoral neck adjacent to the calcar can be unpredictable. These screws get incarcerated because of the abnormal shearing forces causing them to bend and/or due to bony ingrowth. Planning is extremely crucial for a successful and uneventful surgery and requires special instruments. These are not always available in resource poor setups.

In a resource-limited setting, it is essential to have a good knowledge of the instruments at your disposal and put together a screw removal set using readily available instruments (Figure 7). The technique that we employed was simple, quick, preserved bone, and is easily reproducible at any centre and in other fractures.

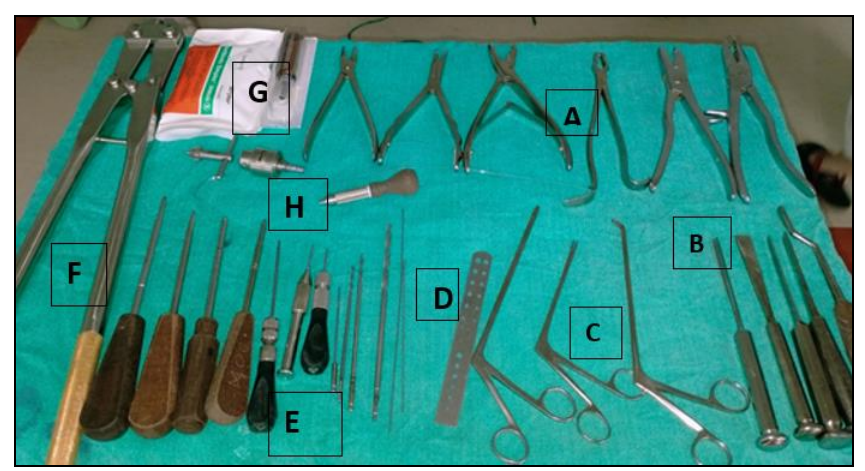

Fig 7: Self-made screw removal set - A) Clamps, pliers and nibbler B) Osteotome and bone gouge C) Nasal and ear forceps D) $\mathrm{K}$ wires, drill bits(all sizes) E) Screwdrivers(Cannulated, solid)(Star/hexagonal /cross) F) Jumbo wire rod cutter G) Cement H) Drill chuck, T-handle, chuck key and quick couple.

\section{References}

1. Zhou L, Tan J, Xu B. [Treatment of femoral neck fracture with cannulated screw fixation in young adults]. Zhongguo Xiu Fu Chong Jian Wai Ke Za Zhi 2007;21(3):275-7.

2. Moehring HD, Althausen PL, Lindholm SR. Technique for Removal of Cannulated Screws: Journal of Orthopaedic Trauma 2005;19(4):280-1.

3. Stafford P, Norris BL, Nowotarski PJ. Hardware Removal: Tips \& Techniques in Revision Fracture Surgery. Techniques in Orthopaedics 2002;17(4):52230.

4. Haseeb M, Butt MF, Altaf T, Muzaffar K, Gupta A, Jallu A. Indications of implant removal: A study of 83 cases. Int J Health Sci (Qassim) 2017;11(1):1-7.

5. Vos DI. Indications for Implant Removal after Fracture Healing. 23.

6. Juan PM, Victor RV, Jorge ML, María AEE, Rafael MC, Luis GLJ, et al. Complications and associated risk factors at screw removal in slipped capital femoral epiphysis treated by cannulated stainless steel screws. Journal of Children's Orthopaedics. 2012 Aug 1 [cited 2021, 17
7. Gopinathan NR, Dhillon MS, Kumar R. Surgical Technique: Simple Technique for Removing a Locking Recon Plate With Damaged Screw Heads. Clin Orthop Relat Res 2013;471(5):1572-5.

8. Bhutta MA, Dunkow PD, Lovell ME. A simple technique for removal of screws with damaged heads. Ann R Coll Surg Engl 2003;85(3):207.

9. Pattison G, Reynolds J, hardy J. salvaging a stripped drive connection when removing screws. Injury 1999;30(1):74-5.

10. Jago RD, Hindley CJ. The removal of metalwork in children. Injury 1998;29(6):439-41.

11. Kaleel S, Ahmed N. A Technique to Remove Cannulated Screws. annals 2006;88(3):320-1.

12. Tomar L, Govil G, Dhawan P. Incarcerated Cannulated Cancellous Screw Removal during Total Hip Arthroplasty with a Novel Trick: A Case Report. Malays Orthop J 2021;15(1):128-31.

13. Chen Y, Giri KP, Pearce CJ. A Novel Surgical Technique for Removing Buried Cannulated Screws Using a Guidewire and Countersink: A Report of Two Cases. Open Orthop J 2015;9:210-3.

14. Yang ZH, Hou FS, Yin YS, Zhao L, Liang $X$. Minimally invasive removal of a deep-positioned cannulated screw from the femoral neck: A case report. World Journal of Clinical Cases 2021;9(18):4760-4.

15. Gruber MA, Starkweather KD, Iii AH, Haralabatos S. Percutaneous screw removal in slipped upper femoral epiphysis 1996;78(1):3. 